\title{
Incidence of delirium in postoperative patients treated with total knee and hip arthroplasty
}

\author{
Felipe de Santana Bosmak ${ }^{1 *}$, Patrick Teller Gibim ${ }^{1}$, Sandra Guimarães ${ }^{1,2}$, Adriano Luiz Ammirati ${ }^{1}$ \\ ${ }^{1}$ Escola de Medicina da Universidade Anhembi Morumbi, São Paulo, SP, Brazil \\ ${ }^{2}$ Department of Internal Medicine, Hospital Santo Antônio, Beneficência Portuguesa de São Paulo, São Paulo, SP, Brazil
}

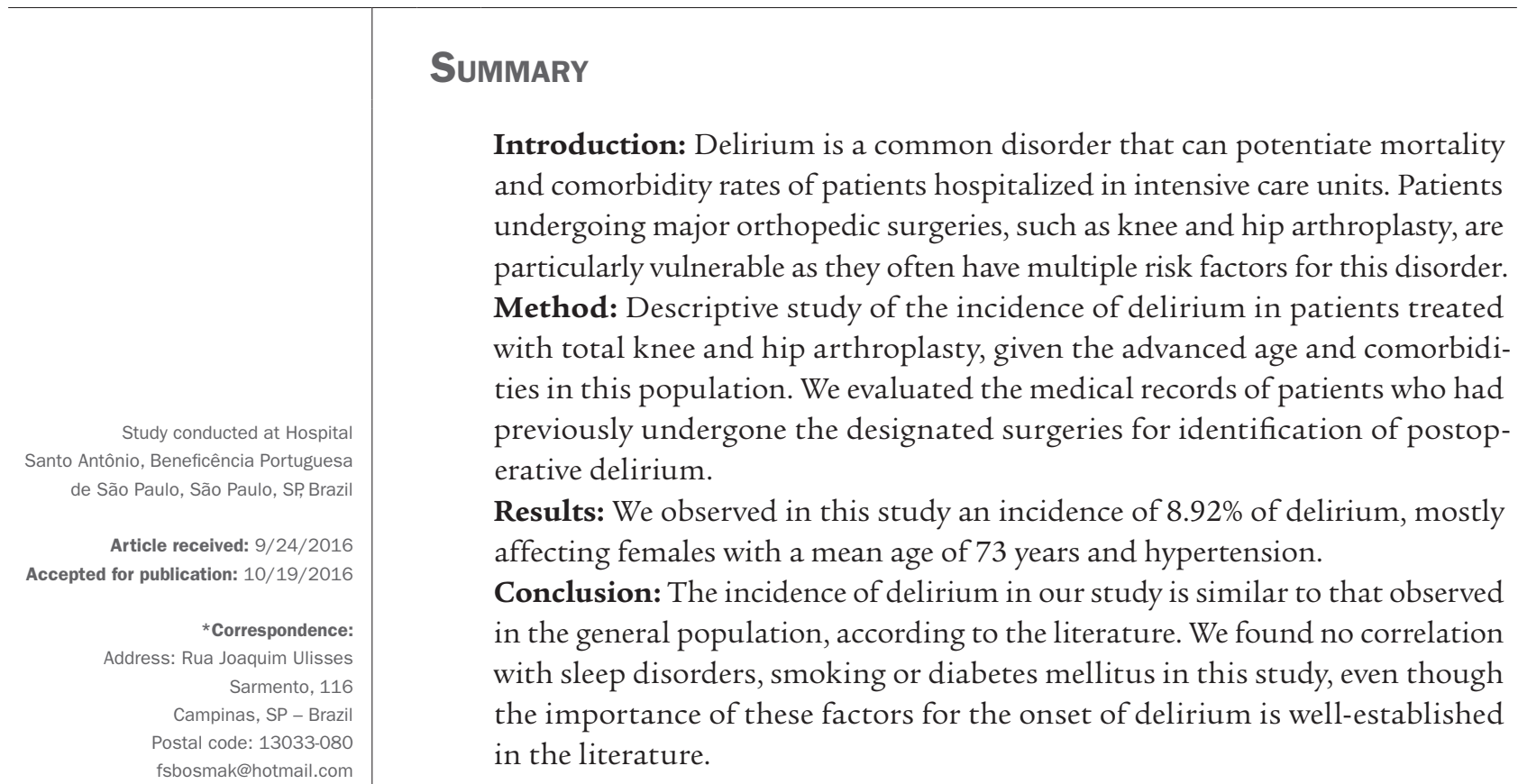

Keywords: delirium, confusion, arthroplasty, orthopedics, intensive care unit.

\section{INTRODUCTION}

Delirium, also known as an acute state of mental confusion, is a cognitive disorder characterized by sudden onset, fluctuating course, and disturbances in level of consciousness, attention, orientation, memory, thought, perception and behavior. It affects people aged 65 and over, mainly. ${ }^{1-4}$ This is a serious disorder, since its prognosis is associated with high rates of mortality, morbidity and prolonged hospitalizations. The costs generated are high for the healthcare system, about 164 billion dollars per year in the United States. ${ }^{1,5}$

The concept of delirium has evolved based on clinical observations and, after years of inaccurate terminology, the diagnosis has been codified in the Diagnostic and Statistical Manual of Mental Disorders (DSM) ${ }^{6,7}$ Since a full psychiatric evaluation is often too long and exhaustive, ${ }^{7,8}$ a more effective means of diagnosis based on the criteria contained in the DSM-III-R, the Confusion Assessment Method $(\mathrm{CAM}),{ }^{7,8}$ has been described. The method was later used in 4,000 publications, being extensively validated, and obtained a sensitivity of $94 \%$ and a specificity of $89 \% .{ }^{6,7}$

Patients at risk for the development of delirium are those undergoing orthopedic surgeries due to fractures or osteoarthrosis, including total knee and hip arthroplasty, which often have several risk factors for delirium observed early in the preoperative period., ${ }^{3,9-12}$

Knee and hip arthroplasties aim to treat chronic refractory pain in these joints. Osteoarthrosis, which has a high incidence in Brazil, commonly causes this type of pain, and the most frequent comorbidity found in these patients is high blood pressure (HBP). ${ }^{13}$ Considering the high average age in this population ( 71 years $)^{13}$ and the relevant presence of comorbidities in this age group, ${ }^{14} \mathrm{a}$ high incidence of delirium in the postoperative period of these patients is to be expected.

Knowing the incidence of delirium in this population can provide better pre and postoperative planning to efficiently allocate resources and prevent the development 
of delirium, as well as improve postoperative management, with the least impact that this disorder can cause. ${ }^{7,11,15}$

\section{Method}

The present study was based on the retrospective evaluation of medical records of patients treated with knee or hip arthroplasty between April and December 2015 at Hospital Santo Antônio, which is part of Hospital Beneficência Portuguesa de São Paulo.

The study was developed after approval by the Ethics Committee of Hospital Beneficência Portuguesa de São Paulo (Santo Antônio unit). Search for references, elaboration of theoretical assumptions, data collection, results, discussion and conclusion were carried out under weekly guidance.

The patients included in our study were those treated with orthopedic surgeries for total knee and hip arthroplasty from April to December 2015. The age range of the study participants was 18 to 90 years, without distinction of gender or color. Diagnoses that included descriptions such as "confused and agitated," "confused and disoriented," "confused and drowsy" and "periods of confusion" were considered delirium. Patients who had a diagnosis of "confusion" or "drowsiness" in the immediate postoperative period were excluded, given the high probability that these alterations were related to the anesthesia used in the surgeries.

In order to prepare an epidemiological profile for the cases of delirium presented in our study, we collected data from the medical literature containing the main risk fac- tors already established in the current literature. Age, chronic diseases such as HBP, sleep disorders, smoking and medication use were all factors evaluated when cited in the medical records. ${ }^{2,11,12,16-22}$

The results obtained were tabulated and their descriptive evaluation performed using Microsoft Excel software (Microsoft Corp., USA), and the appropriate comparisons were made.

\section{Results}

Records of 56 patients were analyzed, with a predominance of females (58.92\%, 33 patients) versus $41.07 \%$ males (23 patients). Mean age was 63 years, the youngest patient being 42 years old and the oldest, 84 years old.

Of the patients evaluated, 25 underwent knee arthroplasty, 10 patients in the right knee (RKAT) and 15 in the left knee (LKAT), while 31 underwent hip arthroplasty, 16 in the right hip (RHAT) and 15 in the left hip (LHAT) (Chart 1).

There were five cases of delirium, totaling $8.92 \%$, of which one was male and four female. The mean age was 73.4 years, ranging from 58 to 80 years. The mean body mass index (BMI) was 29.75, ranging from a minimum of 19.98 to a maximum of 40.5. Three patients had delirium on the second postoperative day, one patient on the first postoperative day, and one patient on the fourth day. The latter had a diagnosis of urinary tract infection. Two were submitted to LKAT, two to RHAT and one to RKAT. Only one of the patients had sleep disorders, and one patient was not suffering from hypertension and did

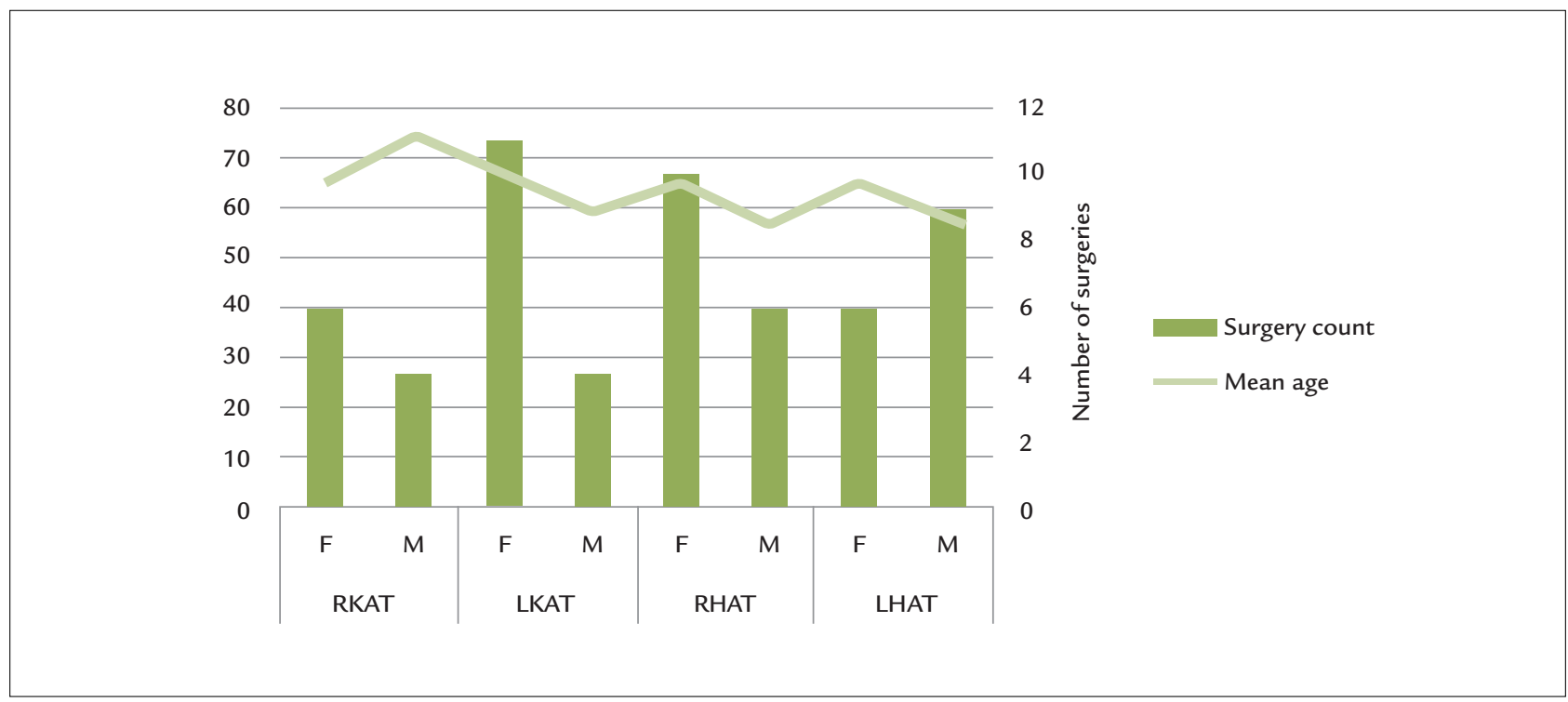

CHART 1 Surgery count and mean age per type of surgery.

RKAT: right knee arthroplasty; LKAT: left knee arthroplasty; RHAT: right hip arthroplasty; LHAT: left hip arthroplasty. F: female; M: male. 
not use previous medication. The most common medication used among them was losartan (four patients) and other drugs to control HBP. In our sample, none of the patients who had delirium were smokers or had diabetes mellitus (Table 1).

\section{TABLE 1 Characteristics of the population.}

\begin{tabular}{llll} 
& & With delirium & Without delirium \\
\hline Sex & $M(n)$ & $20 \%(1)$ & $44.23 \%(23)$ \\
\cline { 2 - 4 } & $F(n)$ & $80 \%(4)$ & $55.76 \%(29)$ \\
\hline Age (Mean) & 73.4 & 62.67 \\
\hline BMI (Mean) & 29.75 & 29.15 \\
\hline Sleep disorders $(n)$ & $20 \%(1)$ & $30 \%(15)$ \\
\hline HBP $(n)$ & $80 \%(4)$ & $73.07 \%(38)$ \\
\hline DM $(n)$ & $0 \%(0)$ & $19.23 \%(10)$ \\
\hline Smokers $(n)$ & $0 \%(0)$ & $7.69 \%(4)$ \\
\hline
\end{tabular}

BMI: body mass index; HBP: high blood pressure; DM: diabetes mellitus; F: female; M: male

\section{Discussion}

In our study, an incidence of $8.92 \%$ of delirium was observed. Most of the patients were female, with a mean age of 72 years and had HBP. We could not observe a relation with sleep disorders, diabetes mellitus, smoking or laboratory abnormalities in this population.

Although there are no studies on the incidence of delirium specifically in patients in the postoperative period of knee and hip arthroplasty, we can indicate that the incidence was in accordance with the literature regarding the general adult population. The incidence was found to be 10 to $24 \%$, whereas in the general surgical population the reported incidence is 37 to $46 \% .^{18,23}$

Studies show that advanced age is one of the factors for the occurrence of delirium, as well as increased mortality from this cause, ${ }^{19}$ which is in agreement with the findings of our study, where the mean age was over 65 years. The increase in age in the general population and the number of diseases related to this increase ${ }^{14}$ may lead to an increase in the incidence of delirium, since chronic organic diseases, ${ }^{13}$ such as HBP, are risk factors.

Metabolic and hydroelectrolytic alterations, although not observed in our study, are reported in the literature as important risk factors for elderly patients suffering from delirium, ${ }^{24}$ with the most reported being hypo or hyperglycemia, hypo or hypernatremia, as well as hypo or hypercalcemia.

Sleep disorders are also cited as a risk factor for delirium. ${ }^{23}$ Except that we did not observe the occurrence of smoking or diabetes mellitus in patients diagnosed with delirium. ${ }^{2,11,12,16-22}$
To better understand the pattern of incidence of delirium in this population, comparison with data collected from other hospitals, countries and at other times would be essential, given that knee and hip arthroplasties are elective surgeries and may be subject to such variations. However, this is a complex evaluation involving heterogeneous populations and differences in method, health system and other factors that vary from region to region or even between hospitals and specialized centers. Nevertheless, descriptive analyses of the pattern of incidence of delirium can assist in the effective allocation of resources, as well as serve as the basis for more elaborate studies on the subject.

Our study is limited by the method of collecting sample data (medical records), which in some cases did not allow us to obtain all the data for a more in-depth analysis or to establish a correlation with other factors mentioned here, though it did reveal an incidence never reported in the current literature for this specific population. A second limitation was that the diagnosis of delirium was performed by the physician responsible for the case, with no information regarding method, which may influence the incidence estimate. However, the description of the diagnosis of delirium was observed, making our study possible.

Considering that knee and hip arthroplasty procedures, due to the use of prostheses, and delirium are clinical situations that burden health services, ${ }^{13}$ associated with the fact that the restrictions of economic resources lead to a greater emphasis on cost-effectiveness, ${ }^{25,26}$ we advocate the need for further studies on the incidence and epidemiology of delirium in this population.

\section{Conclusion}

The incidence of delirium found in our study was compatible with the findings of other authors who analyzed the general adult population, and it may be inferred that, in patients undergoing orthopedic surgery for knee and hip arthroplasty, the incidence of delirium is closer to that of the general population compared with general surgical populations. Nevertheless, larger studies are needed to obtain statistical data on the incidence of delirium, thus providing better comparisons.

Factors such as age, the presence of chronic disease, in our case HBP, and of sleep disorders are relevant for the occurrence of delirium in the postoperative period. Although we found no significant value for the presence of smoking and diabetes mellitus in this study, the importance of these factors for the onset of delirium is well stated in the literature. 


\section{Resumo}

Avaliação da incidência de delirium no pós-operatório de pacientes submetidos a artroplastia total de joelho e quadril

Introdução: Delirium é um transtorno comum e que pode potencializar a taxa de mortalidade e de comorbidade de pacientes internados em unidades de terapia intensiva. Dentre esses pacientes, aqueles submetidos a cirurgias ortopédicas de grande porte, como as artroplastias de joelho e quadril, apresentam especial vulnerabilidade, já que em muitos casos os pacientes são portadores de diversos fatores de risco para esse transtorno.

Método: Este é um estudo descritivo retrospectivo da incidência de delirium em pacientes submetidos a artroplastia total de quadril e joelho, tendo em vista a idade avançada e a presença de comorbidades nessa população. Avaliamos o prontuário de pacientes que foram submetidos anteriormente às cirurgias designadas, para identificar casos de delirium pós-operatório e elaborar este estudo descritivo.

Resultados: Observamos uma incidência de 8,92\% de delirium em sua maioria em pacientes do sexo feminino e com média de idade de 73 anos, portadores de hipertensão arterial.

Conclusão: A incidência de delirium neste estudo assemelhou-se à observada na população geral em outros estudos da literatura. Não foi possível estabelecer uma correlação com distúrbios do sono, diabetes melito, ou tabagismo, apesar de a importância desses fatores para o acometimento de delirium já estar bem-estabelecida na literatura.

Palavras-chave: delírio, confusão, artroplastia, ortopedia, unidade de terapia intensiva.

\section{RefEREnCES}

1. Inouye SK, Westendorp RGJ, Saczynski JS. Delirium in elderly people. Lancet. 2014; 383(9920):911-22.

2. Hölttä EH, Laurila JV, Laakkonen ML, Strandberg TE, Tilvis RS, Pitkala KH Precipitating factors of delirium: stress response to multiple triggers among patients with and without dementia. Exp Gerontol. 2014; 59:42-6.

3. Sieber FE. Postoperative delirium in the elderly surgical patient. Anesthesiol Clin. 2009; 27(3):451-64.
4. Lôbo RR, Silva Filho SRB, Lima NKC, Ferriolli E, Moriguti JC. Delirium. Medicina (Ribeirao Preto). 2010; 43(3):249-57.

5. Lee E, Kim J. Cost-benefit analysis of a delirium prevention strategy in the intensive care unit. Nurs Crit Care. 2014; doi: 10.1111/nicc.12124.

6. Lipowski ZJ. Delirium, clouding of consciousness and confusion. J Nerv Ment Dis. 1967; 145(3):227-55.

7. Javedan H, Tulebaev S. Management of common postoperative complications: delirium. Clin Geriatr Med. 2014; 30(2):271-8.

8. Inouye SK, van Dyck CH, Alessi CA, Balkin S, Siegal AP, Horwitz RI. Clarifying confusion: the confusion assessment method. A new method for detection of delirium. Ann Intern Med. 1990; 113(12):941-8.

9. Schuurmans MJ, Duursma SA, Shortridge-Baggett LM, Clevers GJ, Pel-Littel R. Elderly patients with a hip fracture: the risk for delirium. Appl Nurs Res 2003; 16(2):75-84.

10. Chung KS, Lee JK, Park JS, Choi CH. Risk factors of delirium in patients undergoing total knee arthroplasty. Arch Gerontol Geriatr. 2015; 60(3):443-7.

11. Colón-Emeric CS. Postoperative management of hip fractures: interventions associated with improved outcomes. Bonekey Rep. 2012; 1:241.

12. Oh ES, Li M, Fafowora TM, Inouye SK, Chen CH, Rosman LM, et al. Preoperative risk factors for postoperative delirium following hip fracture repair: a systematic review. Int J Geriatric Psychiatr. 2015; 30(9):900-10.

13. Lenza M, Ferraz SB, Viola DC, Garcia Filho RJ, Cendoroglo Neto M, Ferretti M. Epidemiology of total hip and knee replacement: a cross-sectional study. Einstein (São Paulo). 2013; 11(2):197-202.

14. Brasil. Departamento de Atenção Básica. Envelhecimento e saúde da pessoa idosa. Brasília: Ministério da Saúde; 2007.

15. Gottschalk A, Hubbs J, Vikani AR, Gottschalk LB, Sieber FE. The impact of incident postoperative delirium on survival of elderly patients after surgery for hip fracture repair. Anesth Analg. 2015; 121(5):1336-43.

16. Nandi S, Harvey WF, Saillant J, Kazakin A, Talmo C, Bono J. Pharmacologic risk factors for post-operative delirium in total joint arthroplasty patients: a case-control study. J Arthroplasty. 2014; 29(2):268-71.

17. Veiga D, Luis C, Parente D, Fernandes V, Botelho M, Santos P, et al. Delirium pós-operatório em pacientes críticos: fatores de risco e resultados. Rev Bras Anestesiol. 2012; 62(4):469-83.

18. Silva RFLC, Moreira LR. Fatores de risco para ocorrência de delirium em idosos na terapia intensiva. Enfermagem Rev. 2012; 15(1):102-21.

19. Wang NY, Hirao A, Sieber F. Association between intraoperative blood pressure and postoperative delirium in elderly hip fracture patients. PLoS One. 2015; 10(4):e0123892.

20. Zaal IJ, Devlin JW, Peelen LM, Slooter AJ. A systematic review of risk factors for delirium in the ICU. Crit Care Med. 2015; 43(1):40-7.

21. Kamdar BB, Niessen T, Colantuoni E, King LM, Neufeld KJ, Bienvenu OJ, et al. Delirium transitions in the medical ICU: exploring the role of sleep quality and other factors. Crit Care Med. 2015; 43(1):135-41.

22. Whitlock EL, Vannucci A, Avidan MS. Postoperative delirium. Minerva Anestesiol. 2011; 77(4):448-56.

23. Ramos LR, Cendoroglo MS. Guia de geriatria e gerontologia. 2. ed. São Paulo: Manole; 2011

24. Higashi H, Barendregt JJ. Cost-effectiveness of total hip and knee replacements for the Australian population with osteoarthritis: discreteevent simulation model. PLoS One. 2011; 6(9):e25403.

25. Ryttberg L, Diamantopoulos A, Forster F, Lees M, Fraschke A, Björholt I Cost-effectiveness of rivaroxaban versus heparins for prevention of venous thromboembolism after total hip or knee surgery in Sweden. Expert Rev Pharmacoeconom Outcomes Res. 2011; 11(5):601-5.

26. Kwong L. Cost-effectiveness of rivaroxaban after total hip or total knee arthroplasty. Am J Manag Care. 2011; 17(Suppl 1):S22-6. 